\title{
The Development Status and Problems of
}

\section{Current Digital Artistic Design}

\author{
Yitao Zhou \\ School of Art, South-Central University for Nationalities, Wuhan 430074, China \\ E-mail: 1xy87306548@sina.com
}

\begin{abstract}
The entrance of digital technique into design field brings about tremendous changes, which are mainly shown in the view style of the mixture of objects and viewers. From this perspective, the formation of virtual images depends on computer calculation without any technique difficulties. The support of digital techniques pushes the development of online design mutual actions where culture holds its ground. Designers should shoulder their social responsibilities for loss of home land language design languages and its design context. We need to face all of the problems in the development process of digital artistic design need and to reflect on ourselves.
\end{abstract}

Keywords: Digital image technique, Design, Vision

Digital technique and digital image technique have been widely applied in the entire design field. Computers are replacing traditional pens and paper. The convenience of digital technique and the newness of digital image technique make every designer feel excited. However, the perplexity faced by digital artistic design also worries designers. Starting from this consideration, this paper makes deep analysis on the current status and problems in digital artistic design from the four aspects and tries to develop full discussion.

\section{Virtual idol}

Digital image technique could endless overthrow daily visual experience because digital graphics are not to materialize objects as we commonly mean. The formation of images depends on the permutation and combination in digital arithmetic and the desired images are shown instantly on the screen when you operate a keyboard and mouse. Digital technique could make images in two dimension plan generate multi-dimensional and constantly changing novel visual images and could also break down three dimension shapes into two dimension plane. Also, there are a lot of other similar surprising graphics view, which could not be realized with traditional painting experience. Such technique also provides forceful technique support for us to deviate from daily visual experience.

In the one hundred years history of modernism painting, although there have been various schools, all visual judgment of each art talent depends on overthrowing daily visual experience. Artistic images are no longer the imitation and under of normal world but are to part from the world and make the world strange. Daily reality and artistic representation are no longer of mirror-and-image relationship as of classic art. In these artistic works, we could not see real life and could only feel the joys and sorrows of life in the works full of imagination. Therefore, modernism paintings focus on the difference between real normality and artistic shapes so as to keep the distance of view and at the same time to inspire the visual intellect and imagination of viewing and the viewed.

The reason why digital image technique could deviate from daily visual experience is the great differences in view styles. In the virtual space where human beings and computers mutual act, the quality sense, quantity sense, light, and shadows of the imitation images created by computers are quite the same as reality. Therefore, the psychological driving at scene when the mutual actions take place gives people illusion of sense organs. The border between virtual scene and real scene disappear in the process of mutual action so that people could not keep the distance of view. Bernheim expounds the interposition of digital technique from the perspective of aesthetics and the view styles change accordingly. "The deep artistic meaning of computers lies in that it forces us to doubt the artistic view and reality view of classic art. "(Bernheim, 2002) Through the platform where human beings and computers act mutually, computers "mix up the learners and the learning objects, mix up internal and external concepts, and deny the imagination that requires absolute objectivity. Human beings have realized that daily world is showing the sameness with artistic conditions." (Bernheim, 2002) Actually, the body and heart in the formation of virtual images are separate. Objects of different forms are combined together to form a picture. However, the body could not enter the virtual materialization circumstance to touch them and could only feel them with hearts. Hence, object-and-viewer mixing up of virtual imitation in digital technique is different from the real representation in classic realistic painting art and is different from 
image alienation in modernism painting. Compared with the deviation of modernism painting from daily visual experience, the view styles are different. One keeps certain distance and the other mixes up objects and viewers and put viewers into the circumstances. Although in virtual pictures and scenes, viewers could not enter into the circumstances, the view distance has already disappeared. Compared with classic painting, the two are both realistic. However, one is the real representation of reality and the other is the virtual visual imagination. Because digital images are not free from the restriction of material objects, digital image technique could make normal graphics and could also create pictures beyond imagination. Through mutual means, the novel images generated instantly could constantly change and form new images. Those images could represent life reality and could also imagine future endlessly.

The significant meaning of visual reform brought about by digital image technique lies in that it changes former view style and brings about together various artistic representation styles. Although it is difficult to forecast the final development status of constantly changing digital graphics technique, it is sure that digital image technique provides abundant possibilities for our artistic changes.

\section{Tool for the masses}

When digital image technique encountered visual deign for the first time, they became close sweetie for the masses. Those who could not express their meanings with pictures and are in corners become extremely excited in human being and computer love world. Computers eliminate people's fear in the former hand painting skills. The digital image tools save common people from the imperfectness of painting skills.

In the past, there is such a saying in this field, "from the level of painting skills, 'technique is thoughts'. Only techniques of high level could perfectly express thoughts". For common people, the perfection of techniques and the free expression is the afflictive life of creation because technique requires long term and hard practice. If some one, without special gift and practices, could have similar technique with masters, then digital technique is the magic weapon. In digital era, there is no gap between the techniques of maters and chelas. What the chelas lack is the taste and vision.

Because of digital image technique, the master craft which was too high for others to achieve in the past becomes the technique seasoning for common people. If some one is interested in it, in the process of human being and computer mutual action, she or he could manage to apply the super techniques of various masters. Hence, the pass for entering technique palace disappears. Therefore, we could see such a scene. In the past, the artistic palace usually only has several artistic master-hands, while in the artistic world, there lacks people with super crafts and people are practicing. However, at present, due to the appearance of digital technique, countless heroes step onto the stages. With digital tools, people could achieve craft paradise. At present, digital technique gradually becomes the technique suitable for the masses. However, the feelings between human beings and computers could not eliminate the track of machines. In hand-painting ere where people believe "technique is thoughts", because people advocate the experience in the hand-making process, all to be presented could be fully demonstrated in the process. However, in digital era, the images do not have the amorous feelings in hand-making era and computers replace the aesthetic experiences where hands operate.

In the book designs, all designs could not avoid the stark digital masks. The reasons are that they apply similar computer graphics, they put all together in format and they use sudden sense stimulation. The taste of culture could not be represented by the pictures formed by computers. Obviously, it is the result of simply applying digital techniques. The design for books where computers replace human brains make the expression and meanings more and more plane in the rational restraint of tools. If feelings could be calculated, be forecasted and be controlled in computer codes, the spirit happiness will degrade to Macdonald fast food. The Macdonald phenomenon of designs is the urgent issue to be resolved. The core of Macdonald mode is, within certain standard, to purse the maximum efficiency. All individual and abnormal behaviors are excluded from being resolved. All need to pass the quantity standard. Therefore, all hamburgers of Macdonald in the word have the same taste, which means that culture is excluded. Designs without different cultures could not represent the richness of feelings. Although computer solves the difficulties in design technique, the technique of digital imitation could not show the deep insight of sensibility. Oliver Grau commented in his book Virtual Art that, "computers might become the best storage from-only if the operation system or storage media are not out of date-however, they could not record or copy the materialized art feelings. (Grau, 2007) Although the images from the screen could be materialized, the feeling expression of images created by computers is not so good as those created by hand.

In hand-painting era, craft is the print of soul. The style expression of craft could represent feelings and the craft operation process is the process for heart image and object image to combine, which maybe the connotations of "technique is thoughts". The digital imitation craft seems to be real, however, it is not the representation where heart and object matches and it is just the calculation of digital and saw tooth feelings. Although at present computers start to have the possibilities of random changes, its intellect is just the arithmetic under fixed programs and it just has intelligence quotient but has no affection quotient. Computer is just a type of tool. Therefore, the love between human beings and computers are still experiencing torment in the purgatory of love. 


\section{Mutual Share}

Up to present, the broad band media with sound and vision and other feeling styles together promotes internet entire framework development. Real time mutual action network platform provides great convenience to home land design communication and also provides new ways and methods for the globalization cooperation of design field. Although there is spatial distance, online design could reach places thousands miles away in instance. In mutual action platform, mutual share and real time communication are completed at the same time. The two parties at the platform could together penetrate into the problems, and could inspire innovation in the debate of different concepts. Obviously, on line design international cooperation, with mutual actions of different cognition styles, could enlarge the possibilities of eliminating the design perplexities.

For online design, its convenient spatial change and active dialogue style impress all participants on line. Therefore, the on line cooperation of network platform has its special advantages. The first one is that on mutual action platform, through the mutual functions of external design experience and through borrowing others' view point to examine the current common design concepts, we could find home land design blind points with wider vision. The second is that in economic globalization era, through on line design to learn the consumption demand and cognition attitude under different cultural background, within professional information scale, there is no need to filter motley information so as to rapidly fix new design orientation, which is the basic premise for home land design to walk from region to the world.

When digital design master-hands are searching for the inspiration of creation on line, they are facing a problem: the two parties in network spaces have deviated from real life circumstances. Their mutual communication is culture experience and on the scene description. Even on line design is just the mutual actions of professional experience. On the network, there is no materialized experience in person and the comprehensive life feelings are replaced by language description. However, experience description could not completely and truly reflect the existence of objects. Therefore, facing the screen, the culture experiences of the two parties could not replace the deep insight felt in real life.

The current domestic design, who is trying to escape from the influence of western design languages, has not formed complete home land design language system while advocating Chinese design resources. In on line mutual design, under the circumstance where the communication is unilateral and the information is not symmetrical, there is no lasting and deep treatment and independent judgment. The home land design awareness, held originally, gradually disappear in the aggressive western design context through network mutual action. At this time, the part on the line where is a receiver unconsciously becomes the target audience of western design language. They are not parallel mutual participants. Ester Harjitai mentioned when he made analysis on the reasons for the generation of number gap, "the strength of the U.S. users exceeds the strength of any other culture. therefore, the rules and beliefs of the U.S. culture is quite popular on the internet. Therefore, with dazzling network design resources, instant mutual actions thousands of miles away, and the diversified design experience description, if on the line we do not hold on to home land design language, the western design languages will further invade the base of home land culture. Obviously, only through focusing on home land national design, accumulating design language resources and constructing self design language system could the mutual action on the network has its true design culture status.

\section{Design context}

In era where thoughts are emancipated, we did not stay for a long time and hurried to transfer scattered thoughts into eternal dribs and drabs. When the economy change era came, the consumption tide also came, which drives people to drift in the material desire river. To return to the spirit land and live there happily has become the hope of spirit watcher. Culture steps down from holy palace to common places and culture condition changes accordingly. Cultural context changes from traditional feeling expression to instance sense organ stimulation. From the perspective of design, design context is formed through the accumulation of design activities under practice. In these activities, the methods, ways and technique that are usually applied are the representation of design language. Therefore, design language is the composing element in design context. For current common designs, book design wonders between profit and fashion. The pursuit of commercial profit makes all become consumption, which forces book designs to search for new methods in order to occupy market.

To attract readers' attention within several seconds becomes an important index to judge whether the design is successful. Visual bomb is popular design fashion. "The direct reflecting image apperception is faster than language thinking in receiving time - imagination" (You, 2008). Based on the aforementioned, the emphasis on image functions is actually following the road of popular culture. it uses visual happiness and stimulating images to hide history and thought depth and eliminate the multi-thought apperception so as to force the cultural spirit function of design to loss its meaning and to change the inner spirit demand into external fashionable packing. The wide application of digital graphics technique provides great convenience to wide application of images. Hence, the images on the cover is not the extension and expression of contents in the book. Only if it simulates sense organs to convert it into visual sense of happiness, any visual elements could not be related to the contents in the book. Under such circumstances, the visual expression of all contents in design naturally becomes dialogues of cartoon. Actually, to stimulate sense organs to 
acquire some happiness is not a bad thing. What is terrible is that digital image technique mixes up the border becomes real existence and digital images. Through various medias, it convinces people that the virtual illusive scene is daily life and transfers the view distance into experience in person. The uncontrollable desire and abreaction comes quietly. The beautiful girls on the magazine covers accidentally become the readers' lovers in dream. Even some people are addicted to the beautiful girls. Therefore, the visual happiness under contemporary cultural context should not be the only design language.

Actually, various value tropism in contemporary design context all start from the demands of human beings. However, it is for the designers to think what kind of design demands and design tropism of which level should be taken. With the involvement of digital graphics technique, the openness of design forms the basic tone of contemporary design context. The multi-tropism in design languages becomes common demand. However, design should shoulder the responsibility to promote social progress. In multi-tropism design languages, human beings' basic value judgment could not be lost. The humanism care in design works should be represented in the harmonious relationship between human beings and nature and in the full exhibition of human demands. However, such demand should be common public demand. The ways to resolve problems in current design context are to face the openness of digital technique and to fix home land national culture status so as to shoulder social responsibilities and to construct self language resources.

\section{References}

Bernheim, J.W. (2002). Intelligent system Aesthetics. From Tonybee's The Future of Art. Translated by Wanng, Zhihe. Guiyang: Guangxi Normal University Press, p.72.

Grau, Oliver. Virtual Art. Translated by Chen Ling. Beijing: Tsinghua University Press. (2007), p.152.

Harjitai, Ester. (2003). Network Hole: Network and International Layers. From Understanding Digital Number Gap Technique Colonization and Social Differentiation by Cao Rongxiang. Shanghai: Shanghai Sanlian Bookshop, p.41.

You, Xilin. (2008). Network Surfing Sudden Death Reasons - Modern Reading Time Opposite Theory. From Standpoint by Yu Hong and Xu Xingyan. Beijing: Central Editing and Translation Press, p.154. 